\title{
Comparação da qualidade fisiológica de sementes de soja convencional e de sua derivada transgênica ${ }^{1}$
}

\author{
Tereza Cristina de Carvalho ${ }^{2 *}$, Camila Ribeiro de Souza Grzybowski², \\ Osvaldo de Castro Ohlson ${ }^{3}$, Maristela Panobianco ${ }^{2}$
}

\begin{abstract}
RESUMO - Os avanços na pesquisa têm resultado em várias opções práticas ao agricultor moderno, como o surgimento da soja transgênica. No entanto, vem sendo levantada a hipótese de que sementes de soja convencional, e sua versão transgênica RR, apresentam diferenças quanto à qualidade fisiológica. Dessa maneira, objetivou-se comparar a qualidade fisiológica de sementes de soja convencional e sua derivada transgênica RR, por meio de vários testes empregados na análise de sementes. Para isso, foram utilizados oito lotes de sementes de soja, sendo quatro lotes da cultivar CD 206 e quatro da cultivar CD 206 RR, produzidas no Estado do Paraná. As sementes foram avaliadas quanto ao grau de umidade, curva de embebição e comportamento nos testes de germinação, emergência de plântulas em casa de vegetação, tetrazólio (viabilidade e vigor), envelhecimento acelerado e pelos índices de velocidade de germinação e velocidade de emergência. Com base nos resultados obtidos, concluiu-se que as sementes de soja convencional apresentaram potencial fisiológico superior em relação às da derivada transgênica.
\end{abstract}

Termos para indexação: Glycine max, germinação, vigor, trangênica.

\section{Comparison of physiological quality of soybean seeds and their transgenic derivatives}

\begin{abstract}
Advances in research have resulted in several practical alternatives for the modern farmer, including the development of transgenic soybeans. However, the hypothesis that conventional soybean seeds and their transgenic RR have physiological quality differences has been raised and the objective of the present study was to compare the physiological quality of conventional and transgenic RR soybean seeds. Eight seed lots were used, four from cultivar CD 206 and four from cultivar CD 206 RR, both produced in Paraná State. Seed quality was evaluated from the moisture content, imbibition curve, germination, greenhouse seedling emergence, tetrazolium (viability and vigor), premature aging, germination speed indicators and speed of emergence. We conclude from the results that the conventional soybean seeds had a higher physiological potential than the transgenic derivatives.
\end{abstract}

Index terms: Glycine max, germination, vigor, transgenic.

${ }^{1}$ Submetido em 01/04/2011. Aceito para publicação em 10/08/2011.

${ }^{2}$ Departamento de Fitotecnia e Fitossanitarismo, Universidade Federal do Paraná, 80035-050 - Curitiba, PR, Brasil.
${ }^{3}$ Laboratório de Análise de Sementes Oficial da Empresa Paranaense de Classificação de Produtos, 80035-060 - Curitiba, PR, Brasil.

*Autor para correspondência <tcdcarva@gmail.com> 


\section{Introdução}

Atualmente, no Brasil, das culturas de verão a soja é a que apresenta maior crescimento em área de cultivo, com 24,08 milhões de hectares (safra 2010/11) e produção estimada em 68,55 milhões de toneladas (CONAB, 2011). Com o progresso tecnológico da agricultura brasileira, verifica-se que grande parte da soja produzida é de origem transgênica. Assim, o avanço na área de cultivo da soja transgênica ocupou 20,15 milhões de hectares, ou seja, mais de $80 \%$ de toda área de produção na safra 2010/11 (Rocher, 2010).

A soja transgênica Roundup Ready (RR) trata-se de uma planta geneticamente modificada que apresenta resistência ao herbicida glifosato (Bervald et al., 2010), sendo esta a principal característica que a diferencia da soja convencional. O incentivo à adoção de cultivares transgênicas de soja RR baseia-se na facilidade de manejo de áreas infestadas com plantas daninhas.

Na literatura, parte dos estudos já realizados, comparando o comportamento da soja convencional e sua versão transgênica RR, abordou diferenças na produtividade (Lima et al., 2008), no custo operacional (Menegatti e Barros, 2007) e no teor de lignina do tegumento das sementes (Gris et al., 2010), No entanto, são escassas as informações de pesquisas que contrastem a qualidade fisiológica de sementes de cultivares convencionais e suas respectivas versões transgênicas RR.

Gris et al. (2010) compararam sementes de soja após atingirem a maturidade fisiológica (estádios R7, R8 e 20 dias após R8), utilizando cinco linhagens convencionais e suas respectivas versões transgênicas RR, concluindo que tanto as cultivares convencionais quanto suas versões transgênicas apresentaram o mesmo comportamento, ou seja, com o atraso da colheita houve reduções na germinação e no vigor das sementes. Os mesmos autores destacaram o comportamento da qualidade das sementes da soja convencional e sua derivada transgênica manteve-se similar.

A semente da soja transgênica foi desenvolvida na década de 1980, sendo produzida pela incorporação de um gene exótico, tornando-a apta a produzir novas substâncias e a tolerar o herbicida glifosato. Segundo Menegatti e Barros (2007), essa alteração do genoma pode ocasionar comportamento distinto da planta transgênica, quando comparada ao organismo original. No entanto, verifica-se que o maior argumento para adoção da soja transgênica no Brasil é a redução no custo de produção; entre os argumentos negativos, menciona-se a baixa produtividade da soja transgênica em relação à sua versão convencional (Silveira e Resende, 2010).

A qualidade das sementes reflete diretamente no resultado final da cultura (Andreoli et al., 2002); sendo assim, torna-se fundamental confrontar a qualidade fisiológica das sementes convencionais e sua derivada transgênica, uma vez que a semente contribui decisivamente para o estabelecimento do estande desejado, sendo a base para uma produção rentável (Marcos-Filho, 2005).

Neste sentido, objetivou-se nessa pesquisa comparar a qualidade fisiológica de sementes de soja convencional e sua derivada transgênica RR, produzidas no Estado do Paraná.

\section{Material e Métodos}

A pesquisa foi conduzida no Laboratório de Análise de Sementes do Departamento de Fitotecnia e Fitossanitarismo, da Universidade Federal do Paraná, em Curitiba-PR, no período de junho a dezembro de 2010. Foram utilizados oito lotes de sementes de soja (safra 2009/2010), sendo quatro lotes da cultivar CD 206 e quatro lotes da cultivar CD 206 RR (essencialmente derivada da cultivar convencional), produzidas em regiões distintas do Estado do Paraná, a saber: Cascavel, Guarapuava, Londrina e Ponta Grossa.

A qualidade inicial das sementes dos oito lotes foi avaliada por meio do teste de germinação, de acordo com metodologia proposta por Brasil (2009), utilizando-se quatro repetições por lote. Assim, os lotes pertencentes às cultivares em estudo foram inicialmente separados em alta viabilidade (germinação acima de $94 \%$ ), viabilidade intermediária (germinação entre $87 \%$ a $92 \%$ ) e baixa viabilidade ( $80 \%$ de germinação), sendo que cada cultivar tinha um lote de alta viabilidade, dois de viabilidade intermediária e um de baixa viabilidade. Na sequência, para a composição das repetições, a amostra de sementes de cada lote foi homogeneizada em um divisor centrífugo, baseando-se nos critérios estabelecidos nas Regras para Análise de Sementes (Brasil, 2009). Ao final da homogeneização, dividiram-se cada amostra em quatro subamostras (repetições) de peso semelhante, empregando-se novamente o divisor centrífugo, totalizando assim 16 repetições por cultivar.

Posteriormente, as sementes foram acondicionadas em sacos de papel do tipo Kraft e armazenadas em ambiente controlado com temperatura de $14{ }^{\circ} \mathrm{Ce} 63 \%$ de umidade relativa do ar, durante o período experimental, visando minimizar a intensidade de deterioração.

As seguintes avaliações foram realizadas:

Determinação do grau de umidade: realizada pelo método de estufa a $105 \pm 3{ }^{\circ} \mathrm{C}$, por 24 horas, utilizandose duas subamostras de $5,0 \mathrm{~g}$ de sementes para cada repetição (Brasil, 2009). Os resultados foram expressos em porcentagem média para cada cultivar, na base úmida.

Teste de germinação: para cada repetição, foram utilizadas duas subamostras de 50 sementes cada (totalizando assim trinta e duas repetições), distribuídas em rolos de papel toalha 
umedecidos com quantidade de água equivalente a 2,5 vezes a massa do substrato seco e mantidas em germinador, a $25{ }^{\circ} \mathrm{C}$. A contagem das plântulas normais foi realizada diariamente, até o oitavo dia após semeadura (Brasil, 2009). Os resultados foram expressos em porcentagem.

Índice de velocidade de germinação (IVG): determinado durante a condução do teste de germinação, por meio de contagens diárias das plântulas normais até o oitavo dia após a semeadura. O índice de velocidade de germinação foi obtido pela fórmula proposta por Maguire (1962) e os resultados foram expressos em índice médio de velocidade de germinação para cada cultivar.

Teste de tetrazólio (TZ): empregado o procedimento descrito por França-Neto et al. (1998). Para cada repetição, foram utilizadas duas subamostras de 50 sementes cada (totalizando assim 32 repetições). As amostras foram précondicionadas entre papel toalha umedecido, com quantidade de água equivalente a 2,5 vezes a massa do substrato, durante 16 horas, a $25^{\circ} \mathrm{C}$. Em seguida, as sementes foram colocadas em recipientes de plástico e mantidas submersas em solução $0,075 \%$ de cloreto de 2,3,5 trifenil tetrazólio, a $40{ }^{\circ} \mathrm{C}$ no escuro, por 150 minutos. Decorrido esse período, as sementes foram lavadas em água corrente e analisadas uma a uma, computando-se como número de sementes viáveis (viabilidade) as incluídas na classe de sementes de 1 a 5 ; como potencialmente vigorosas (vigor) as incluídas na classe de sementes de 1 a 3 . Os resultados foram expressos em porcentagem de sementes viáveis e vigorosas.

Teste de envelhecimento acelerado: adotada metodologia descrita por Marcos-Filho (1999), com o uso de caixas de plástico como mini-câmaras, possuindo em seu interior uma bandeja de tela de alumínio, onde foram distribuídas as sementes formando camada única, o conjunto foi mantido a $41{ }^{\circ} \mathrm{C}$ e $100 \%$ de umidade relativa do ar, durante 48 horas. Em seguida, foi instalado o teste de germinação conforme descrito acima, sendo que a contagem de plântulas normais foi realizada no quinto dia.

Curva de embebição: conduzida segundo procedimento descrito por Caseiro et al. (2004). Para cada repetição, pertencente a cada lote, foi retirada uma amostra de sementes de $2,5 \mathrm{~g}$. Posteriormente as quatro repetições de $2,5 \mathrm{~g}$ de sementes de cada lote foram misturadas, totalizando assim $10 \mathrm{~g}$ de sementes por lote. As sementes pertencentes a cada lote foram distribuídas entre duas camadas formadas por três folhas de papel toalha cada uma, umedecidas com água em quantidade equivalente a 2,5 vezes a massa do substrato. Esse conjunto foi disposto sobre tela de alumínio instalada no interior de caixas plásticas $(11 \times 11 \times 3 \mathrm{~cm})$ contendo $40 \mathrm{~mL}$ de água, a $25^{\circ} \mathrm{C}$. A marcha de absorção de água foi monitorada por meio de pesagens das sementes em intervalos de 60 minutos até a protrusão da raiz primária e a taxa de embebição foi calculada com base no peso inicial das sementes. Foi considerado o início da protrusão da raiz primária quando pelo menos cinco sementes apresentaram a raiz com comprimento mínimo de $1 \mathrm{~mm}$. Com os dados, foram calculados a curva de embebição e o incremento de massa fresca; sendo este último obtido por meio do quociente entre a massa fresca inicial e a massa fresca final. Os resultados foram expressos pela média dos quatro lotes para cada cultivar.

Emergência de plântulas em casa de vegetação: para cada repetição, foram utilizadas duas subamostras de 50 sementes cada (totalizando assim trinta e duas repetições), distribuídas em bandejas de poliestireno ("isopor") de 128 células, com $2 \mathrm{~cm}$ de profundidade de semeadura, utilizando o substrato Plantmax ${ }^{\circledR}$. As sementes foram mantidas em casa de vegetação, sob temperatura ambiente e com irrigação diária. Foram realizadas contagens diárias das plântulas emergidas até o $14^{\circ}$ dia após a semeadura, sendo considerado como plântula emergida o estádio de emergência VE (Fehr e Caviness, 1980). Com os dados, foram calculados a porcentagem de plântulas emergidas e o índice de velocidade de emergência de plântulas (IVE) conforme proposto por (Maguire, 1962).

Os dados obtidos em cada teste, exceto a determinação do grau de umidade, foram analisados de acordo com delineamento inteiramente casualizado, com 32 repetições, separadamente para cada teste conduzido. Para os resultados da curva de embebição consideraram-se quatro repetições, sendo cada repetição representada por um lote. Os dados obtidos foram submetidos à análise de variância pelo teste de médias. A análise foi realizada sem transformação empregando o sistema computacional ASSISTAT, versão 7.5 beta (Silva, 2008). As médias foram comparadas pelo teste de Scott Knott $(p \leq 0,05)$.

\section{Resultados e Discussão}

Para realizar a comparação do comportamento de sementes da cultivar de soja convencional e sua versão transgênica RR, é importante que o grau de umidade inicial dos lotes de sementes apresente valores semelhantes, conforme revelado na Tabela 1 , uma vez que a uniformidade da umidade é fundamental para a padronização das avaliações e obtenção de resultados consistentes (MarcosFilho et al., 1987). 
Tabela 1. Resultados da determinação do grau de umidade e dos testes de germinação e de tetrazólio (viabilidade) de sementes de soja das cultivares CD 206 e CD 206 RR.

\begin{tabular}{|c|c|c|c|}
\hline \multirow{2}{*}{ Cultivar } & Grau de umidade & Germinação & Tetrazólio (viabilidade) \\
\hline & \multicolumn{3}{|c|}{ 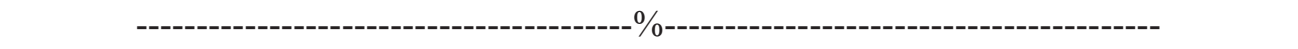 } \\
\hline CD 206 & 11,8 & $92 \mathrm{a}$ & $92 \mathrm{a}$ \\
\hline CD206 RR & 11,2 & $87 \mathrm{~b}$ & $88 \mathrm{~b}$ \\
\hline C.V. $(\%)$ & - & 6,2 & 5,8 \\
\hline
\end{tabular}

Médias seguidas pela mesma letra minúscula na coluna não diferem entre si pelo teste de Scott Knott $(\mathrm{p} \leq 0,05)$.

Na Tabela 1 pode-se verificar que a cultivar convencional apresentou superioridade em relação à sua derivada transgênica quanto à germinação e viabilidade (teste de tetrazólio). No processo de germinação das sementes, a embebição é fundamental para a retomada da atividade metabólica e quanto mais rápida for esta etapa, mais cedo se dará a germinação das sementes (Marcos-Filho, 2005). Neste sentido, a curva de embebição para as sementes CD 206 e CD 206 RR (Figura 1) mostrou que os valores porcentuais do grau de umidade durante o processo de embebição das sementes, de ambas as cultivares, estão muito próximos, não apresentando

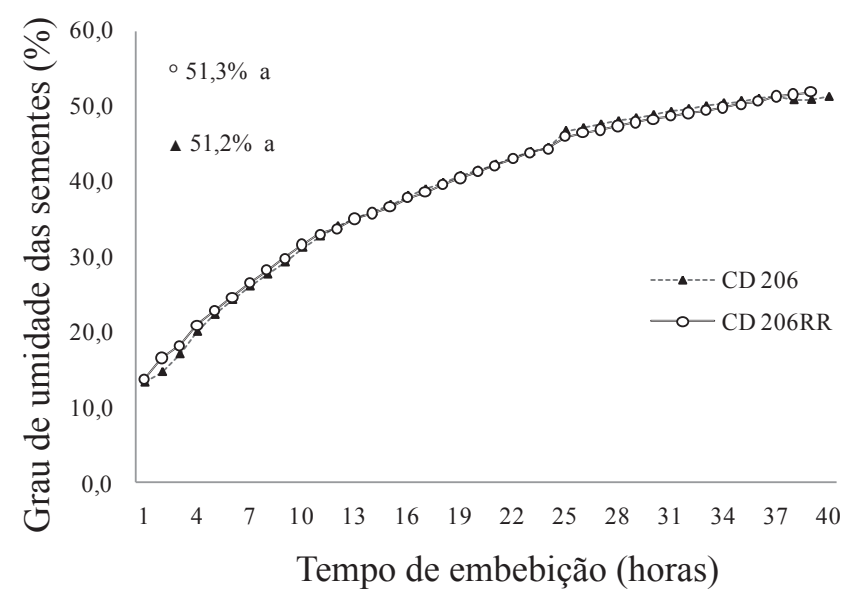

Figura 1. Curva de embebição de sementes de soja, cultivares CD 206 e CD 206 RR. Médias seguidas pela mesma letra minúscula não diferem entre si $(\mathrm{CV}=1,2 \%)$ pelo teste de Scott Knott $(\mathrm{p} \leq 0,05)$.

Analisando-se o vigor das sementes, obtido pelo teste de tetrazólio (Tabela 2), o melhor resultado foi para as sementes da cultivar CD 206, apresentando maior vigor em relação a sua versão transgênica. $\mathrm{Na}$ diferenças estatísticas, e que a protrusão da raiz primária para as sementes transgênicas ocorreu 38 horas após início do teste, enquanto que na sua versão convencional a protrusão deu-se após 39 horas. Resultados similares foram observados para o incremento de massa fresca (Figura 2), evidenciando ganho de massa para as sementes de ambos os genótipos, à medida que as sementes iniciaram o processo de germinação. Entretanto, verifica-se que mesmo não havendo diferença significativa para o início da germinação entre estes dois materiais (Figura 1), a soja convencional apresentou viabilidade superior em relação a sua versão transgênica (Tabela 1).

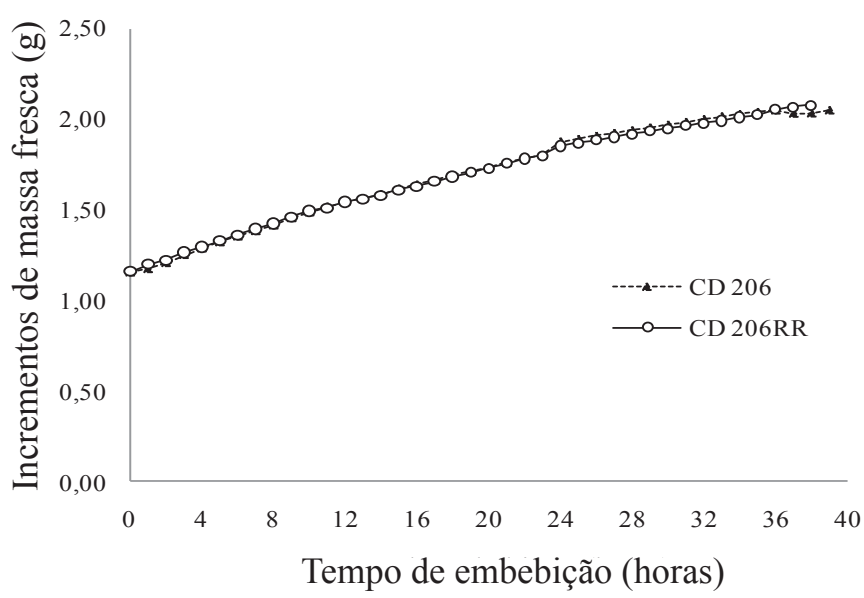

Figura 2. Efeito da embebição de sementes de soja, sobre $\mathrm{o}$ incremento de massa de matéria fresca, para as cultivares CD 206 e CD 206 RR.

classificação de níveis de vigor para sementes de soja (pelo teste de tetrazólio), descrita por França-Neto et al. (1998), as sementes da cultivar convencional caracterizaram-se como de alto vigor (valor entre 
$75 \%$ a $84 \%$ ), enquanto as sementes transgênicas classificaram-se como de vigor intermediário (valor entre $60 \%$ a 74\%). Conforme destacaram Marcos-Filho e Kikuti (2006), o uso de sementes mais vigorosas assegura o estabelecimento adequado das plantas no campo; além das plantas apresentarem maior índice de área foliar, produção de matéria seca e acréscimos de produtividade (Kolchinski et al., 2005).

Tabela 2 - Resultados do vigor, avaliado pelos testes de tetrazólio (vigor), envelhecimento acelerado e emergência da plântula em casa de vegetação, de sementes de soja das cultivares CD 206 e CD 206 RR.

\begin{tabular}{|c|c|c|c|}
\hline \multirow{2}{*}{ Cultivar } & Tetrazólio (vigor) & Envelhecimento acelerado & Emergência de plântulas \\
\hline & \multicolumn{3}{|c|}{---------------------------------------------\%"------------------------------------------- } \\
\hline CD 206 & $80 \mathrm{a}$ & $85 \mathrm{a}$ & $98 \mathrm{a}$ \\
\hline CD 206 RR & $73 \mathrm{~b}$ & $78 \mathrm{~b}$ & $92 \mathrm{~b}$ \\
\hline C.V. $(\%)$ & 10,0 & 7,8 & 3,2 \\
\hline
\end{tabular}

Médias seguidas pela mesma letra minúscula na coluna não diferem entre si pelo teste de Scott Knott ( $\leq \leq 0,05)$.

O teste de envelhecimento acelerado (Tabela 2) também revelou superioridade para as sementes convencionais em relação às transgênicas. Estudos revelaram a confiabilidade deste teste aplicado em sementes de soja para caracterização de diferenças no potencial fisiológico (Marcos-Filho et al., 2001), além de ser um dos mais indicados para a determinação do vigor de sementes (Silva et al., 2010; AOSA, 2002).

A superioridade na qualidade fisiológica das sementes de soja convencional em relação à sua versão transgênica foi verificada, novamente, pelo teste de emergência de plântulas em casa de vegetação (Tabela 2), o qual indicou as sementes convencionais como as de melhor vigor em relação às transgênicas. Observou-se que o teste de emergência de plântulas para as sementes das cultivares convencional e transgênica apresentou médias superiores às observadas no teste de germinação (Tabela 1). Resultados semelhantes foram obtidos por Braccini et al. (1994), que também observaram valores significativamente superiores de viabilidade das sementes de diferentes genótipos de soja, no teste de emergência de plântula em relação aos obtidos no de germinação. Esse resultado pode estar relacionado à infecção das sementes por Phomopsis spp. (França-Neto et. al 1992), visto que a presença do fungo, na maioria dos casos, ocorre apenas no tegumento das sementes de soja, causando variações nos resultados obtidos entre os testes de germinação e o conduzido na areia.

Sabe-se que a qualidade da semente é a soma de diversos atributos que contribuem para obtenção de plântulas mais vigorosas, que apresentam germinação e emergência mais rápida. Tais resultados foram observados para o índice de velocidade de germinação e índice de velocidade de emergência (Tabela 3), no qual as sementes da cultivar convencional foram superiores estatisticamente a cultivar transgênica. Tal fato evidencia crescimento mais rápido de plântulas da cultivar convencional, o que pode favorecê-las em campo, onde ocorre maior competição por luminosidade, nutrientes e água, entre a espécie de cultivo comercial e as plantas invasoras.

Tabela 3. Resultados da velocidade de germinação e de emergência de sementes de soja, das cultivares CD 206 e CD 206 RR.

\begin{tabular}{ccc}
\hline \multirow{2}{*}{ Cultivar } & Índice de velocidade de germinação & Índice de velocidade de emergência \\
\cline { 2 - 3 } & $---0-0$ & $9,0 \mathrm{a}$ \\
CD 206 & $10,0 \mathrm{a}$ & $8,1 \mathrm{~b}$ \\
\hline CD 206 RR & $8,3 \mathrm{~b}$ & 6,5 \\
\hline
\end{tabular}

Médias seguidas pela mesma letra minúscula na coluna não diferem entre si pelo teste de Scott Knott ( $\mathrm{p} \leq 0,05)$. 
$\mathrm{Na}$ atualidade, os avanços mais recentes da pesquisa são com os organismos geneticamente modificados, que por meio do cruzamento de diferentes espécies e a introdução de um gene distinto, iniciam a transformação de um novo comportamento da planta (Manegatti e Barros, 2007). No entanto, a mudança de comportamento no novo indivíduo pode gerar vantagens e desvantagens. Na referida pesquisa, observou-se que a incorporação do gene RR afetou negativamente a qualidade fisiológica das sementes de soja, quando comparada a convencional.

\section{Conclusões}

As sementes de soja convencional CD 206 têm potencial fisiológico superior em relação às da sua derivada transgênica.

\section{Agradecimentos}

À Coordenação de Aperfeiçoamento de Pessoal de Nível Superior (Capes), pelo auxílio financeiro.

\section{Referências}

ANDREOLI, C.; ANDRADE, R.V.; ZAMORA, S.A.; GORDON, M. Influência da germinação da semente e da densidade de semeadura no estabelecimento do estande e na produtividade de milho. Revista Brasileira de Sementes, v.24, n.2, p.1-5, 2002. http://www.scielo.br/ scielo.php?script=sci_arttext\&pid=S0101-31222002000200001\&lng=pt \&nrm $=$ iso \& $\operatorname{tng}=\mathrm{pt}$

ASSOCIATION OF OFFICIAL SEED ANALYSTS. Seed vigor testing handbook. Lincoln: AOSA, 2002. 105p.

BERVALD, C.M.P.; MENDES, C.R.; TIMM, F.C.; MORAES, D.M.; BARROS, A.C.S.A.; PESKE, S.T. Desempenho fisiológico de sementes de soja de cultivares convencional e transgênica submetidas ao glifosato. Revista Brasileira de Sementes, v.32, n.2, p.9-18, 2010. http://www. scielo.br/pdf/rbs/v32n2/v32n2a01.pdf

BRACCINI, A.L.; REIS, M.S.; SEDIYAMA, C.S.; SEDIYAMA, T. Avaliação da qualidade fisiológica e sanitária da semente de genótipos de soja (Glycine max (L.) Merril) com diferentes graus de impermeabilidade do tegumento. Revista Brasileira de Sementes, v.16, n.2, p.195-200, 1994. http://www.abrates.org.br/revista/artigos/1994/v16n2 /artigo16.pdf

BRASIL. Ministério da Agricultura, Pecuária e Abastecimento. Regras para análise de sementes. Ministério da Agricultura, Pecuária e Abastecimento. Secretaria de Defesa Agropecuária. Brasília, MAPA/ACS, 2009. 395p. http://www.agricultura.gov.br/arq_editor/ file/Laborat $\%$ C3\%B3rio/Sementes/Regras $\% 20$ para $\% 20$ Analise $\% 20$ de\%20Sementes.pdf
CASEIRO, R.F.; BENNETT, M.A.; MARCOS-FILHO, J. Comparison of three priming techniques for onion seed lots differing in initial seed quality. Seed Science and Technology, v.32, n.2, p.365-375, 2004. http:// scholar.google.com.br/scholar?q=Comparison $\% 20$ of $\% 20$ three $\% 20$ priming $\% 20$ techniques $\% 20$ for $\% 20$ onion $\% 20$ seed $\% 201$ ots $\% 20$ differing $\% 20$ in $\% 20$ initial $\% 20$ seed $\% 20$ qual $>$

COMPANHIA NACIONAL DE ABASTECIMENTO. Acompanhamento de safra brasileira: grãos, quarto levantamento, janeiro 2011 / Companhia Nacional de Abastecimento. - Brasília: CONAB, 2011. 41p. http:// www.conab.gov.br/OlalaCMS/uploads/arquivos /11_01_06_08_41_56_ boletim_graos_4o_lev_safra_2010_2011.pdf

FEHR, W.E.; CAVINESS, C.E. Stages of soybean development. Ames: Iowa State University, Cooperative Extension Service, 1980. 11p.

FRANÇA-NETO, J.B.; KRZYZANOWSKI, F.C.; COSTA, N.P. O teste de tetrazólio em sementes de soja. Londrina: Embrapa Soja, 1998. 72p. (Embrapa-CNPSo. Documentos, 116).

FRANÇA-NETO, J.B.; HENNING, A.A. DIACOM. Diagnóstico completo da qualidade de semente de soja. Londrina: EMBRAPA, CNPSo, 1992. 22 p. (Embrapa Centro Nacional de Pesquisa da Soja. Circular Técnica, 10).

GRIS, C.F.; VON PINHO, E.V.R.; ANDRADE, T.; BALDONI, A.; CARVALHO, M.L.M. Qualidade fisiológica e teor de lignina no tegumento de sementes de soja convencional e transgênica RR submetidas a diferentes épocas de colheita. Ciência e Agrotecnologia, v.34, n.2, p.374-381, 2010. http://www.scielo.br/scielo.php?script=sci ar ttext\&pid=S1413-70542010000200015

KOLCHINSKI, E.M.; SCHUCH, L.O.B.; PESKE, S.T. Vigor de sementes e competição intra-específica em soja. Ciência Rural, v.35, n.6, p.1248-1256, 2005. http://www.scielo.br/pdf/cr/v35n6/a04v35n6.pdf

LIMA, W.F.; PÍPOLO, A.E.; MOREIRA, J.U.V.; CARVALHO, C.G.P.; PRETE, C.E.C.; ARIAS, C.A.A.; OLIVEIRA, M.F.; SOUZA, G.E.; TOLEDO, J.F.F. Interação genótipo-ambiente de soja convencional e transgênica resistente a glifosato, no Estado do Paraná. Pesquisa Agropecuária Brasileira, v.43, n.6, p.729-736, 2008. http://www.scielo. br/pdf/pab/v43n6/a09v43n6.pdf

MAGUIRE, J.D. Speed of germination-aid in selection and evaluation for seedling emergence and vigor. Crop Science, v.2, n.1, p.176-177, 1962.

MARCOS-FILHO, J. Fisiologia de sementes de plantas cultivadas. Piracicaba: FEALQ, 2005. 495p.

MARCOS-FILHO, J. Teste de envelhecimento acelerado. In: KRZYZANOWSKI, F.C.; VIEIRA, R.D.; FRANÇA-NETO, J.B. (ed.). Vigor de sementes: conceitos e testes. Londrina: ABRATES, 1999. p.1-24

MARCOS-FILHO, J.; CICERO, S.M.; SILVA, W.R. Avaliação da qualidade das sementes. Piracicaba: FEALQ, 1987. 230p. 
MARCOS-FILHO, J.; KIKUTI, A.L.P. Vigor de sementes de rabanete e desempenho de plantas em campo. Revista Brasileira de Sementes, v.28, n.3, p.44-51, 2006. http:/www.scielo.br/pdf/rbs/v28n3/07.pdf

MARCOS-FILHO, J.; NOVEMBRE, A.D.C.; CHAMMA, H.M.C.P. Testes de envelhecimento acelerado e de deterioração controlada para avaliação do vigor de sementes de soja. Scientia Agricola, v.58, n.2, p.421-426, 2001. http://www.scielo.br/pdf/sa/v58n2/4437.pdf

MENEGATTI, A.L.A.; BARROS, A.L.M. Análise comparativa dos custos de produção entre soja transgênica e convencional: um estudo de caso para o Estado do Mato Grosso do Sul. Revista de Economia e Sociologia Rural, v.45, n.1, p.163-183, 2007. http://www.scielo.br/ scielo.php?script=sci_arttext\&pid=S0103-20032007000100008.

ROCHER, J. Brasil Transgênico. Jornal Gazeta do Povo.-Curitiba: Gazeta do Povo, publicado em 14 mar. 2010. http://www.gazetadopovo.com. br/caminhosdocampo/conteudo.phtml?tl=1\&id=1077231\&tit=Brasiltransgenico
SILVA J.B.; LAZARINI, E.; SÁ, M.E. Comportamento de sementes de cultivares de soja, submetidos a diferentes períodos de envelhecimento acelerado. Bioscience Journal, v.26, n.5, p.755-762, 2010. http://www. seer.ufu.br/index.php/biosciencejournal/articl e/viewFile/7187/5265

SILVA, F.A.S. Sistema de Assistência Estatística - ASSISTAT versão 7.5 beta. Departamento de Engenharia Agrícola (DEAG) do CTRN da Universidade Federal de Campina Grande - UFCG, Campina Grande PB, 2008. http://www.assistat.com/. Acesso em: 21 dez. 2010.

SILVEIRA，J.V.F.; RESENDE， L.M. Estratégias de mercado no agronegócio paranaense: soja convencional vs. transgênica. Produção, v.20, n.1, p.54-65, 2010. http://www.scielo.br/pdf/prod/v20n1/aop_200604024.pdf. Acesso em: 10 fev. 2011. 